University of Wollongong

Research Online

Faculty of Engineering and Information

Faculty of Engineering and Information

Sciences - Papers: Part A

Sciences

$1-1-2014$

\title{
Crack healing in a low-carbon steel under hot plastic deformation
}

Hailiang Yu

University of Wollongong, hailiang@uow.edu.au

Xianghua Liu

Northeastern University, liuxh@uow.edu.au

Xinwen Li

Northeastern University

Ajit R. Godbole

University of Wollongong, agodbole@uow.edu.au

Follow this and additional works at: https://ro.uow.edu.au/eispapers

Part of the Engineering Commons, and the Science and Technology Studies Commons

Research Online is the open access institutional repository for the University of Wollongong. For further information contact the UOW Library: research-pubs@uow.edu.au 


\title{
Crack healing in a low-carbon steel under hot plastic deformation
}

\begin{abstract}
The behavior of internal crack healing in low-carbon steel samples undergoing hot plastic deformation was investigated using the MMS 200 thermo-mechanical simulator. The characterization of cracks after plastic deformation was analyzed using scanning electron microscopy under different heating temperatures, reduction ratios, numbers of deformation passes, strain rates, and holding time durations. It was found that the degree of crack healing increases with increasing heating temperature, reduction ratio, and holding time duration, and with decreasing number of deformation passes and strain rate.
\end{abstract}

\section{Keywords}

plastic, hot, under, deformation, steel, crack, carbon, low, healing

Disciplines

Engineering | Science and Technology Studies

\section{Publication Details}

YU, H., Liu, X., Li, X. \& Godbole, A. (2014). Crack healing in a low-carbon steel under hot plastic deformation. Metallurgical and Materials Transactions A: Physical Metallurgy and Materials Science, 45 (2), 1001-1009. 


\title{
Crack Healing in a Low-Carbon Steel Under Hot Plastic Deformation
}

\author{
HAILIANG YU, XIANGHUA LIU, XINWEN LI, and AJIT GODBOLE
}

The behavior of internal crack healing in low-carbon steel samples undergoing hot plastic deformation was investigated using the MMS 200 thermo-mechanical simulator. The characterization of cracks after plastic deformation was analyzed using scanning electron microscopy under different heating temperatures, reduction ratios, numbers of deformation passes, strain rates, and holding time durations. It was found that the degree of crack healing increases with increasing heating temperature, reduction ratio, and holding time duration, and with decreasing number of deformation passes and strain rate.

DOI: $10.1007 / \mathrm{s} 11661-013-2049-4$

(C) The Minerals, Metals \& Materials Society and ASM International 2013

\section{INTRODUCTION}

PROPAGATION and healing of cracks are two contrary processes that occur in materials. Since Griffith proposed the brittle fracture model, the propagation of cracks in materials ${ }^{[1,2]}$ along with the macroscopic, microscopic, and nanoscale aspects of fracture mechanics have attracted considerable research interest. However, the process of crack healing in materials has only been investigated relatively recently. Some investigations have been carried out on crack healing in different materials. ${ }^{[3-5]}$ However, studies on crack healing in steel are comparatively rare, especially under the conditions of metal forming.

Internal cracks in metallic materials can heal without plastic deformation (the voids can gradually disappear) under electric current pulse treatment ${ }^{[6,7]}$ and heat treatment. ${ }^{[8,9]}$ Heat treatment has been employed to restore the plasticity margin destroyed during cold plastic deformation and to avoid damage, ${ }^{[10]}$ and it could be concluded from the experimental data that healing of microdamage in metals had occurred. Some experiments on crack healing in pure iron samples at high temperature were carried out by Zhang et al..$^{[11]}$ Micron-sized internal cracks were introduced into the pure iron samples by application of low-cycle fatigue

HAILIANG YU, Vice-chancellor's Research Fellow, is with the School of Mechanical, Materials and Mechatronic Engineering, University of Wollongong, Wollongong NSW 2500, Australia and also Professor, with the School of Mechanical Engineering, Shenyang University, Shenyang 110044, P.R. China. Contact e-mails: hailiang@ uow.edu.au, yuhailiang1980@tom.com XIANGHUA LIU, Professor, is with the State Key Laboratory of Rolling and Automation, Northeastern University, Shenyang 110004, P.R. China. XINWEN LI, Master Student, formerly with the State Key Laboratory of Rolling and Automation, Northeastern University, is now with the Baosteel, Shanghai, P.R. China. AJIT GODBOLE, Senior Research Fellow, is with the School of Mechanical, Materials and Mechatronic Engineering, University of Wollongong.

Manuscript submitted November 8, 2012.

Article published online October 12, 2013 load. Cracks on grain boundaries were found to have a regular penny-like shape. The fatigued specimens were annealed for 7 hours in vacuum at $1173 \mathrm{~K}\left(900{ }^{\circ} \mathrm{C}\right)$. Scanning electron microscope (SEM) observations showed that the microcracks initially changed to a wavy shape after 2 hours, then evolved into an array of circular voids after 5 hours, and after 7 hours, isolated voids were scarcely observable. Compared with the results of crack healing with heat treatment and no plastic deformation, crack healing with plastic deformation could occur rapidly. Wei et al. ${ }^{[12]}$ carried out a series of experiments on preset internal crack healing in $20 \mathrm{MnMo}$ and 20\# steel samples using the "HIGHMULTI 5000" hot-press equipment. Experimental results showed that the internal cracks could heal completely and only ferrite was discovered in the crack healing zone. Based on the measured stress-strain curves and thermo-physical data of $25 \mathrm{Cr} 2 \mathrm{Ni} 4 \mathrm{MoV}$ steel, a finite element (FE) model of void closure during a heavy forging process was established by $\mathrm{Li}$ et al. ${ }^{[13]}$ They found that the high temperature combined with severe deformation could enhance the ability of atomic transition and reduce the microgap between adjacent surfaces. Hautakangas et al. ${ }^{[14]}$ used the position lifetime and Doppler broadening spectroscopy technique, and found that solute $\mathrm{Cu}$ atoms precipitated in the deformation-induced open-volume defects site and significantly reduced the concentration of voids in an $\mathrm{Al}-\mathrm{Cu}-\mathrm{Mg}$ alloy. Yu et al. ${ }^{[15,16]}$ carried out investigations on the evolution of surface cracks in hot rolling processes. The crack shape and the contact pressure on crack surfaces were analyzed under various rolling conditions.

Currently known mechanisms of healing in metals only lead to healing of defects with a rather small volume. ${ }^{[17]}$ In this study, a series of experiments on internal crack healing in low-carbon steel under hot plastic deformation was carried out using the thermomechanical simulator. Influences of heating temperature, holding time, reduction ratio, strain rate, and number of deformation passes on the crack healing in the material were analyzed using SEM imaging. The 
results provide sufficient basis for further research on internal crack healing and propagating in steel during plastic deformation, and also on quality control in rolled products.

\section{EXPERIMENTAL INVESTIGATION}

The chemical composition of the tested low-carbon steel samples was: C0.15, Si 0.307, Mn 1.33, S 0.07, P 0.014. Samples were prepared as shown in Figure 1: (1) cylindrical workpieces (diameter $8 \mathrm{~mm} \times$ length $7.5 \mathrm{~mm}$ ) were machined; (2) Surfaces marked ' $A$ ' were polished to remove traces of oxidation. Two workpieces were joined to make up the test samples, with the gap between the samples forming the "preset" internal crack.

The experiments on crack healing were carried out for various heating temperatures, holding time durations, reduction ratios, strain rates, and numbers of reduction passes in vacuum using the "MMS 200" thermo-mechanical simulator. Only one of the factors was changed in each set of experiments; all others were kept constant. After the deformation, the samples were removed immediately. The basic simulation parameters are listed in Table I. The degree of healing of the preset internal cracks in the center of samples after deformation was observed using the "QUANTA 600 " SEM. The degree of crack healing was assessed based on the number of residual holes and the appearance of the microstructure in the transition zone. A reduction in the number of residual holes in the transition zone implies a higher degree of crack healing.

\section{RESULTS AND DISCUSSION}

\section{A. Influence of Heating Temperature}

Figure 2 shows SEM micrographs of the preset internal crack zone for different heating temperatures. There is an obvious commencement of crack healing when the heating temperature is $1173 \mathrm{~K}\left(900{ }^{\circ} \mathrm{C}\right)$. At this stage, the macro-crack disappears, but there are many small holes and small grains of size less than $10 \mu \mathrm{m}$, and the microstructure is only ferrite compared with that of the overall matrix. When the heating temperature reaches $1273 \mathrm{~K}\left(1000{ }^{\circ} \mathrm{C}\right)$, the crack healing is clearly better, and fewer and smaller holes remain in the transitional zone where the grain size increases and the microstructure is still ferrite. When the heating temperature reaches $1373 \mathrm{~K}\left(1100{ }^{\circ} \mathrm{C}\right)$, the holes undergo further reduction in size and the microstructure is similar to the matrix of some pearlite. There are no holes in the entire preset crack zone, and the microstructure around the preset crack zone is similar to that of the matrix when the heating temperature reaches $1473 \mathrm{~K}$ $\left(1200{ }^{\circ} \mathrm{C}\right)$. The figures show that the degree of crack healing increases progressively and the transitional zone of crack healing gradually disappears with increasing heating temperature.

The relationship between the number of residual holes and the heating temperature $\left(T_{\mathrm{H}}\right)$ is shown in Figure 3. Curve-fitting yields the following equation:

$$
y=5.04 \times 10^{13} \exp \left(-T_{\mathrm{H}} / 42.16\right)+1.23 .
$$

The deformation resistance of the samples decreases as the heating temperature increases. Thus, the protru-

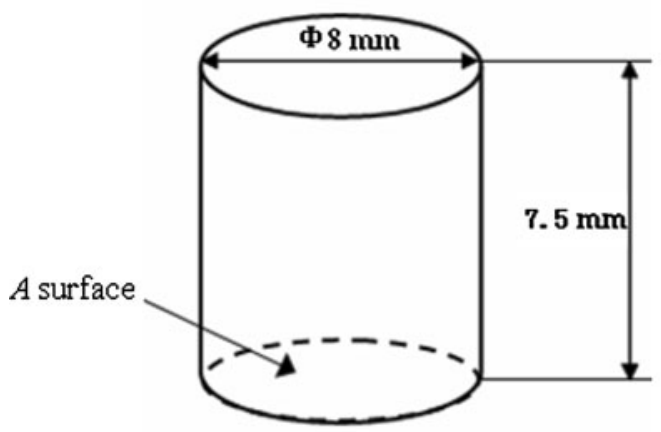

(a)

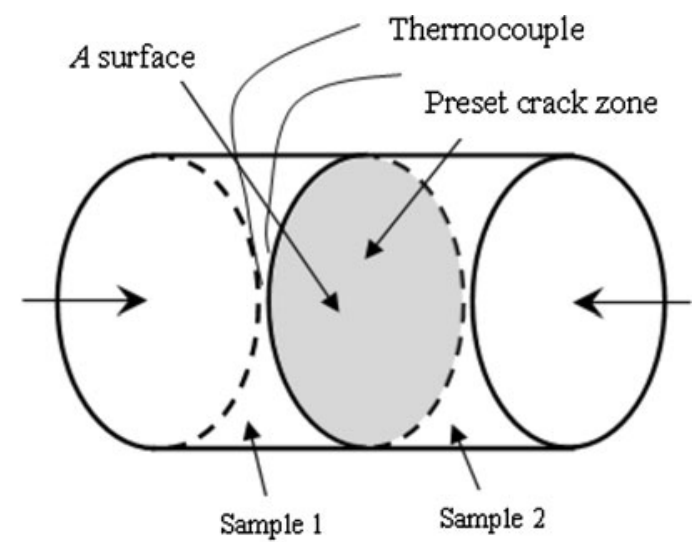

(b)

Fig. 1-Thermo-mechanical experimental samples with preset cracks.

Table I. Thermo-mechanical Simulation Parameters

\begin{tabular}{|c|c|c|c|c|c|c|}
\hline $\begin{array}{l}\text { Strain } \\
\text { Rate }\left(\mathrm{s}^{-1}\right)\end{array}$ & $\begin{array}{l}\text { Heating Temperature } \\
{\left[\mathrm{K}\left({ }^{\circ} \mathrm{C}\right)\right]}\end{array}$ & $\begin{array}{l}\text { Reduction } \\
\text { Ratio (Pct) }\end{array}$ & $\begin{array}{l}\text { Deformation } \\
\text { Pass }\end{array}$ & $\begin{array}{l}\text { Holding } \\
\text { Time (min) }\end{array}$ & $\begin{array}{c}\text { Heating } \\
\text { Rate }(\mathrm{K} / \mathrm{s})\end{array}$ & $\begin{array}{c}\text { Cooling } \\
\text { Rate }(\mathrm{K} / \mathrm{s})\end{array}$ \\
\hline 1 & $1373(1100)$ & 50 & single & 5 & 10 & 5 \\
\hline
\end{tabular}




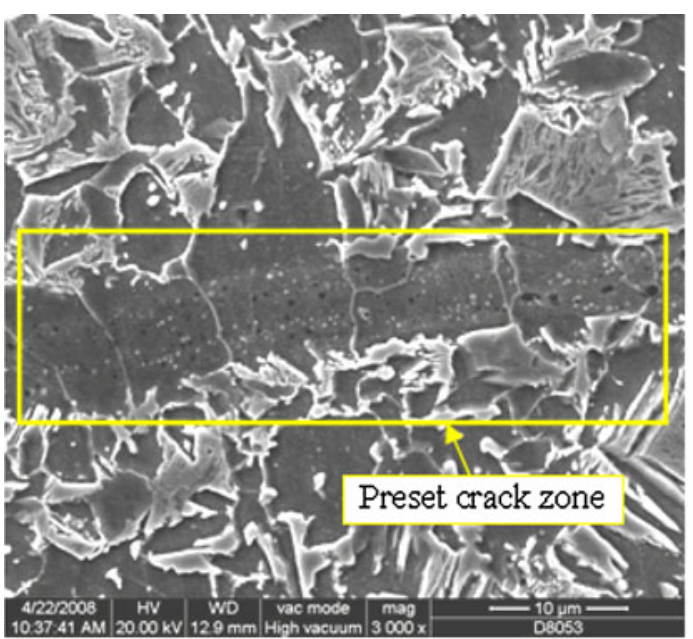

(a) $1173 \mathrm{~K}$

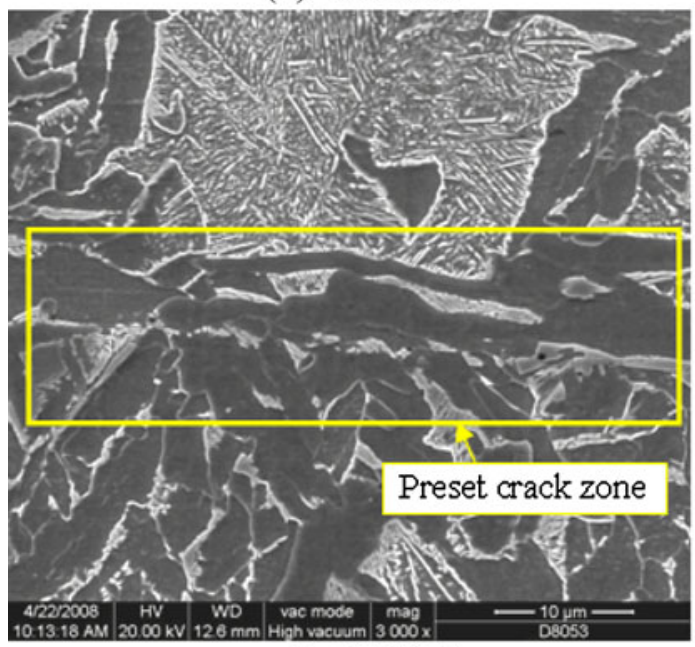

(c) $1373 \mathrm{~K}$

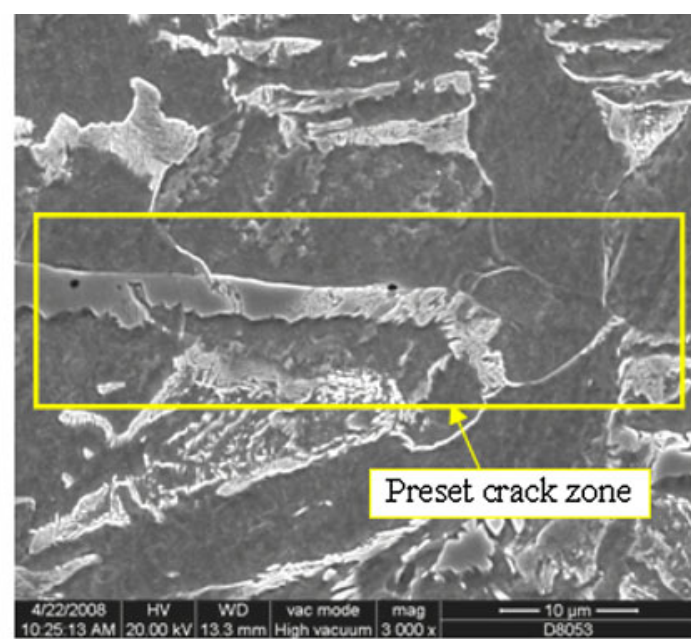

(b) $1273 \mathrm{~K}$

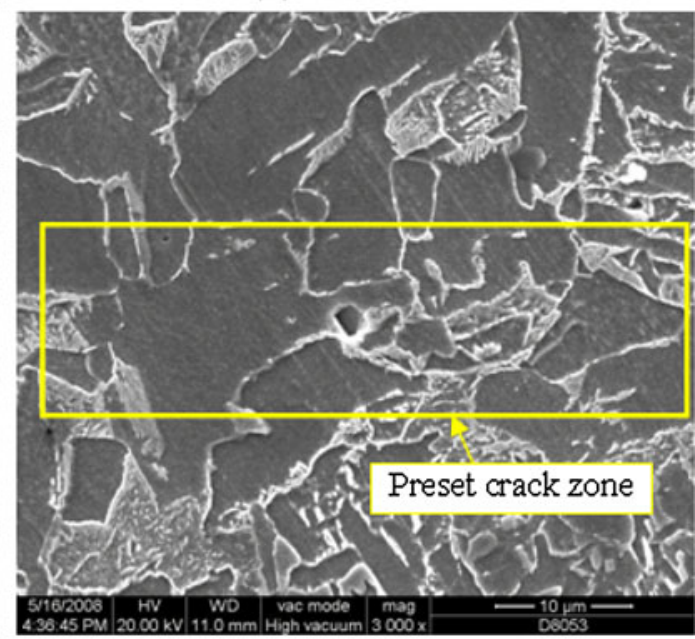

(d) $1473 \mathrm{~K}$

Fig. 2-SEM micrographs of crack healing zone after deformation for various heating temperatures.

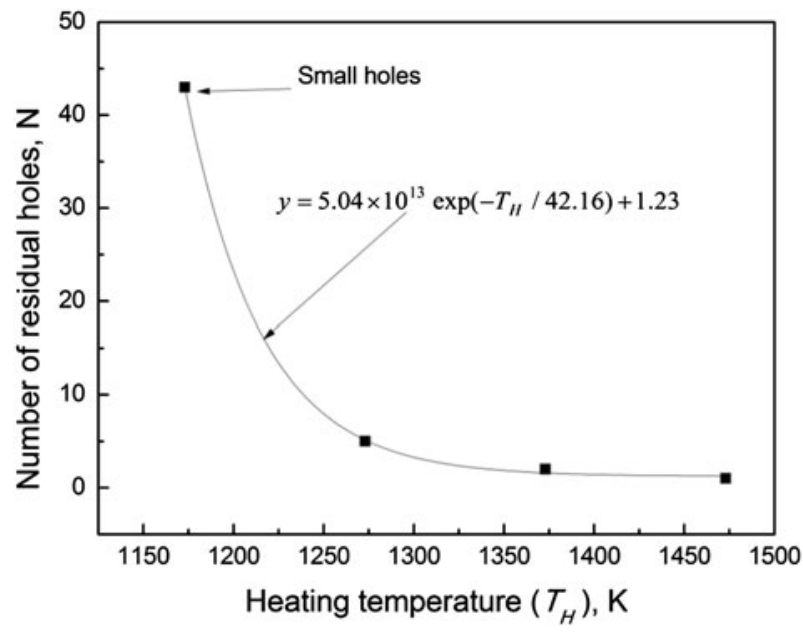

Fig. 3-Number of residual holes in the crack healing zone after deformation as a function of heating temperatures.

sions on the crack surfaces will deform more easily under compression. When the crack contact surface increases, the density of residual holes around the preset crack zone decreases. The relationship between the diffusion coefficient and the heating temperature can be calculated by Arrhenius formula,

$$
D=D_{0} \exp (-Q / R T),
$$

where $D$ is the diffusion coefficient, $D_{0}$ the diffusion constant, $Q$ the molar activation energy of diffusion, $R$ the universal molar gas constant, and $T$ the thermodynamic temperature.

With increasing heating temperature, the atoms on the crack surfaces can migrate more easily, corresponding to the higher diffusion coefficient. This leads to crack healing. Simultaneously, the higher the heating temperature is, the more easily the grains around the preset crack zone grow, which accelerates the migration of defects, and results in narrowing the crack healing transitional zone.

\section{B. Influence of Reduction Ratio}

Figure 4 shows SEM micrographs of the center of the preset internal crack zone of specimens after 
compressive deformation for various reduction ratios. In Figure 4(a), the majority of preset crack zone is still in a disconnected state when the reduction ratio is zero. Although the reduction ratio is set to zero, a very small reduction occurs in the holding process. The temperature around crack surfaces is not uniform due to the non-uniform thermal resistance in the preset crack zone with the current power heating. This induces healing in parts of the preset crack zone. Healing is not seen in the other zones because the normal distance between crack surfaces is too large and the atoms cannot jump directly across the gap. When the reduction ratio is 10 pct, the healing area in the preset crack zone increases, and most parts of preset crack zone bond together. However, the degree of crack healing is not high, and a number of large holes are seen in the preset crack zone, as shown in Figure 4(b). In the compressive deformation process, the protrusions on the crack surfaces come into contact first, which enlarges the contact surface in the preset crack zone, so that the cracks heal due to a combination of atomic diffusion under the stress and thermal gradients. The crack surfaces do not come into full contact for this reduction ratio, leaving some residual holes. SEM micrographs of the crack healing zone shown in Figures 4(c) and (d) correspond to an increased reduction ratio of 20 and 30 pct, respectively. Here, the hole size decreases significantly compared to that in Figure 4(b). It is also seen from Figures 4 (a) through (d) that the microstructure in the crack healing transitional zone consists of only ferrite. ${ }^{[10]}$ When the reduction ratio is 40 pct, it is difficult to detect holes remaining in the preset crack zone after deformation. But there is still an obvious transitional zone whose microstructure is different from the that of the overall matrix. The grain size in the crack healing transitional zone is smaller than that of the matrix, as shown in Figure 4(e). When the reduction ratio reaches $50 \mathrm{pct}$, the grains in the crack healing zone are similar to those in the matrix, whose microstructure is no longer only ferrite, as shown in Figure 4(f).

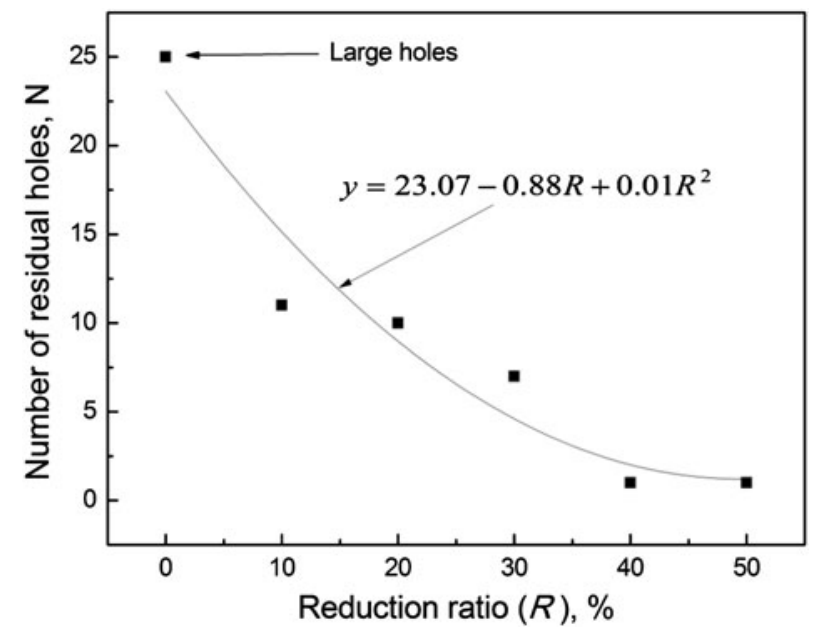

Fig. 5-Number of residual holes in the crack healing zone after deformation as a function of reduction ratios.

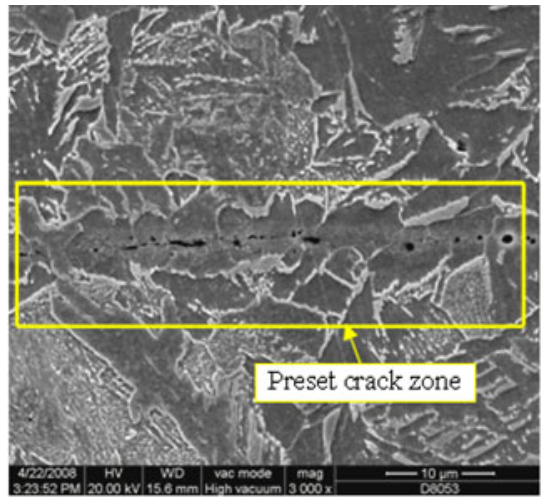

(a) $0 \%$

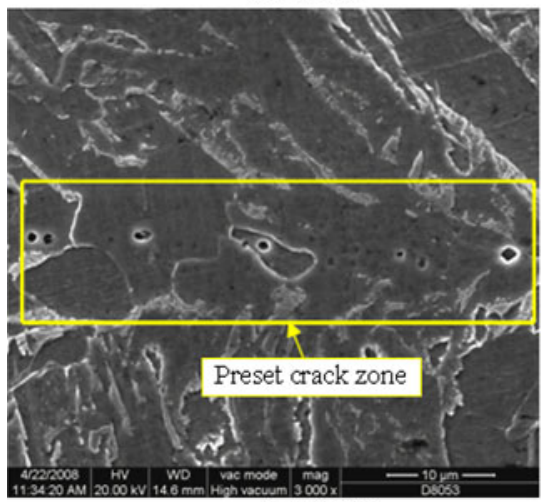

(d) $30 \%$

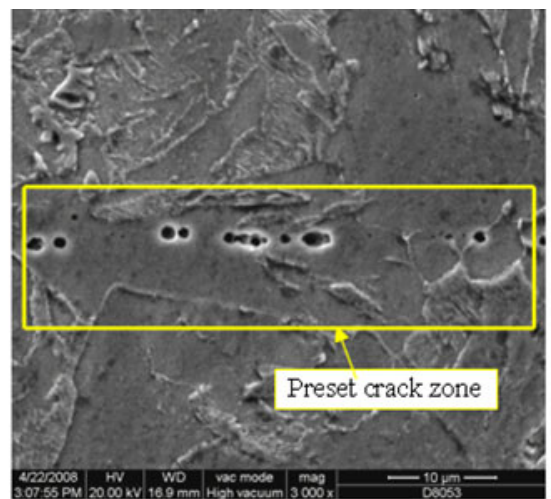

(b) $10 \%$

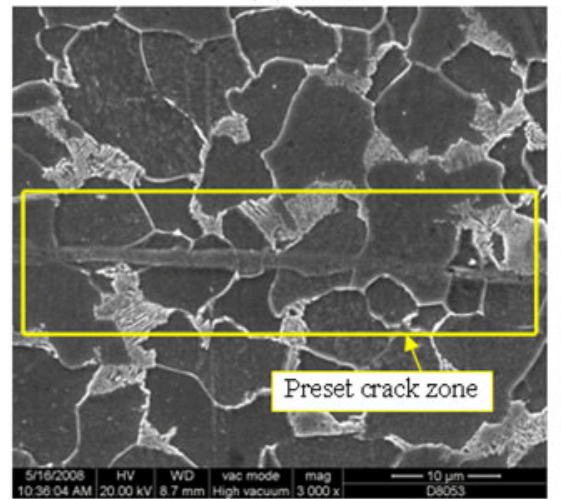

(e) $40 \%$

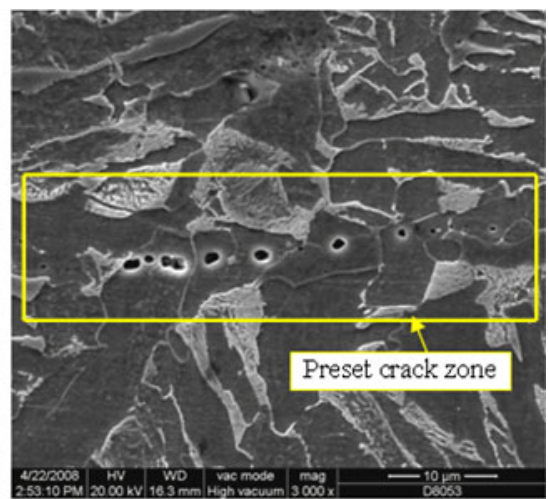

(c) $20 \%$

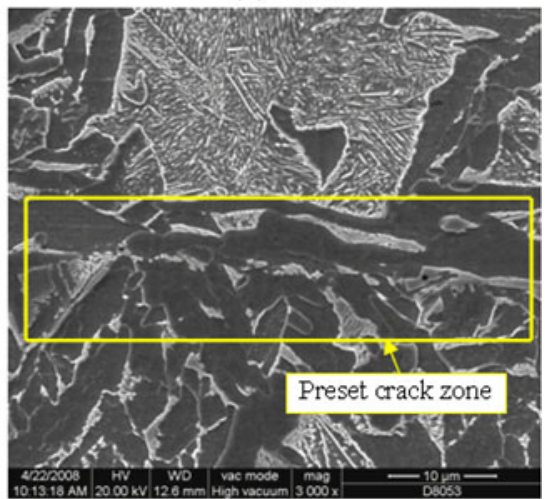

(f) $50 \%$

Fig. 4 -SEM micrographs of crack healing zone for different reduction ratios. 
Figure 5 shows the relationship between the number of residual holes in the crack healing zone and reduction ratio $(R)$, which is fitted well by Eq. [3]

$$
y=23.07-0.88 R+0.01 R^{2} .
$$

It is seen that as the reduction ratio increases, the crack healing degree in the preset crack zone increases, the crack healing transitional zone gradually narrows, and the difference in the microstructure between the transitional zone and the matrix also reduces. With greater reduction ratio, the deformation of the protrusions on the crack surfaces increases, increasing the contact surface. For a given deformation temperature, the diffusion driving force caused by the temperature is unchanged. With increasing deformation, the stress gradient increases, so that the diffusion driving force for atomic diffusion on the crack surfaces increases. This accelerates the formation of bonds across the crack surfaces. At the same time, as the reduction ratio increases, the driving force for atomic diffusion also increases, increasing the energy of the lattice distortion.

\section{Influence of Number of Deformation Passes}

Figure 6 shows SEM micrographs of the preset internal crack zone after compressive deformation for different number of deformation passes, with the total reduction ratio held constant at 50 pct. There are some small holes in the crack healing transitional zone after the fifth deformation pass, 10 pet reduction per pass. When the number of deformation passes is three (reduction schedule $20+20+10$ pct), there are still small holes in the crack healing transitional zone, and the microstructure in the crack healing transitional zone becomes more uniform in the matrix. When the schedule of the deformation is $30+20$ pct (two passes), the holes decrease further in size/number. When the reduction ratio is 50 pct, there are very few holes which remain in the preset crack zone after deformation.

It is seen that the number of holes in the preset crack zone after deformation decreases as the number of deformation pass decreases when the total reduction ratio is constant, so that the crack healing degree improves. The relationship between the number of residual holes and number of rolling pass is approximate linear relationship, as shown in Figure 7. For the same

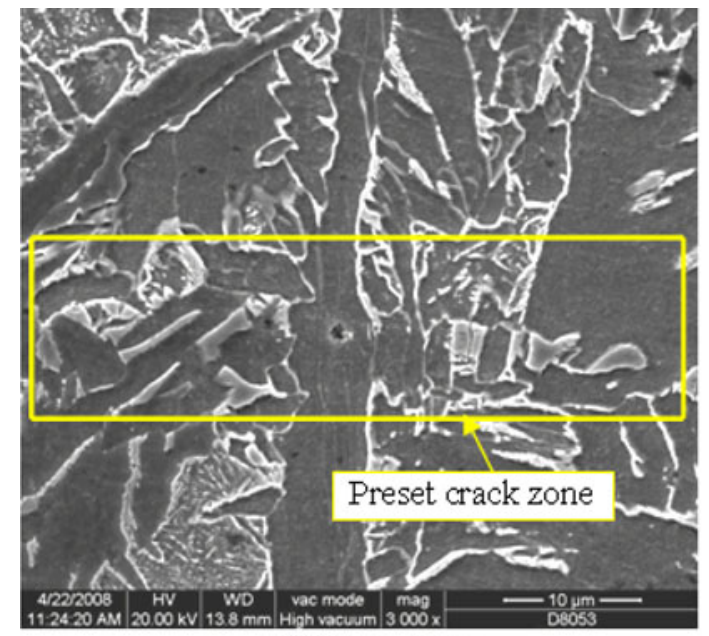

(a) Five pass

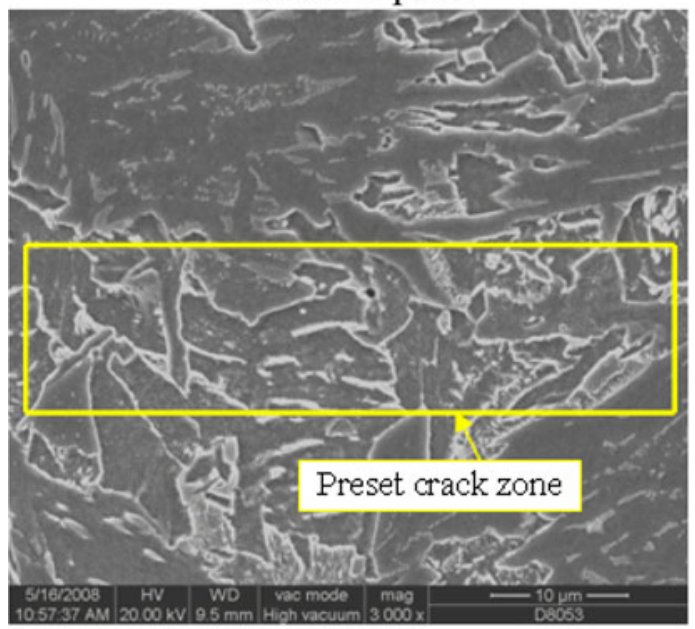

(c) Two pass

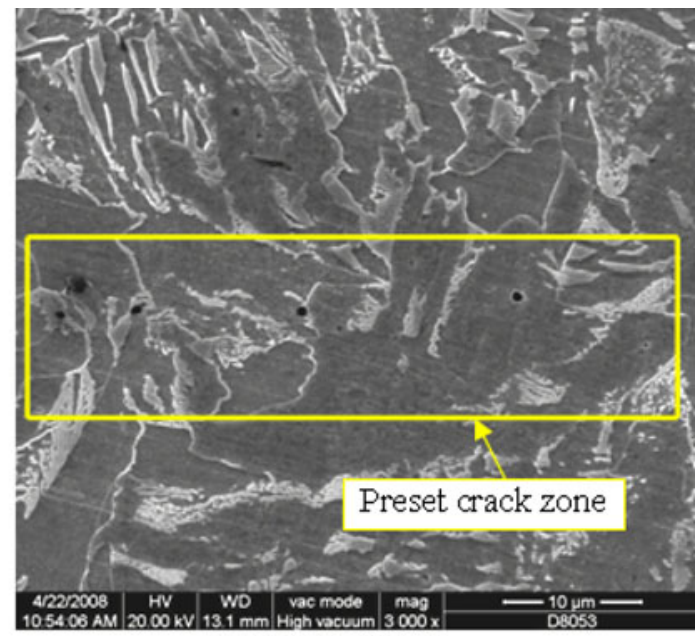

(b) Three pass

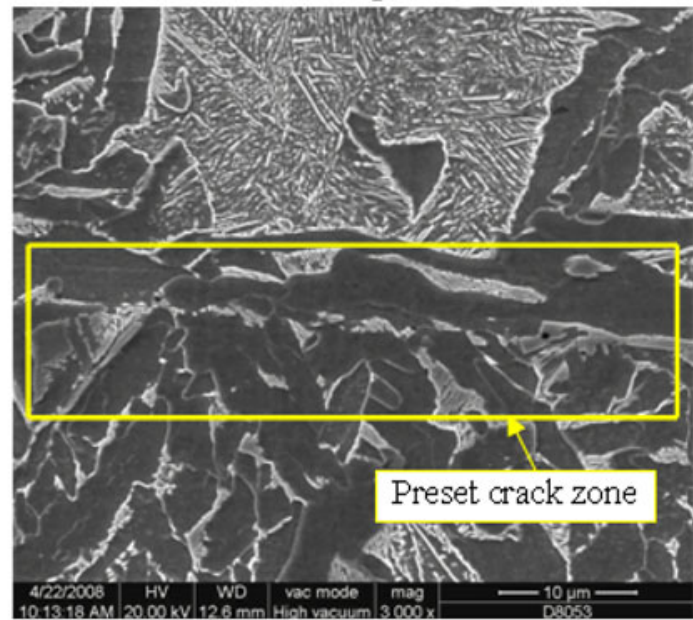

(d) One pass

Fig. 6-SEM micrographs of crack healing zone for various deformation passes with identical total reduction ratio. 
total reduction ratio, the deformation in every pass can be specified; as the number of the deformation pass increases, the deformation in every pass decreases. Due

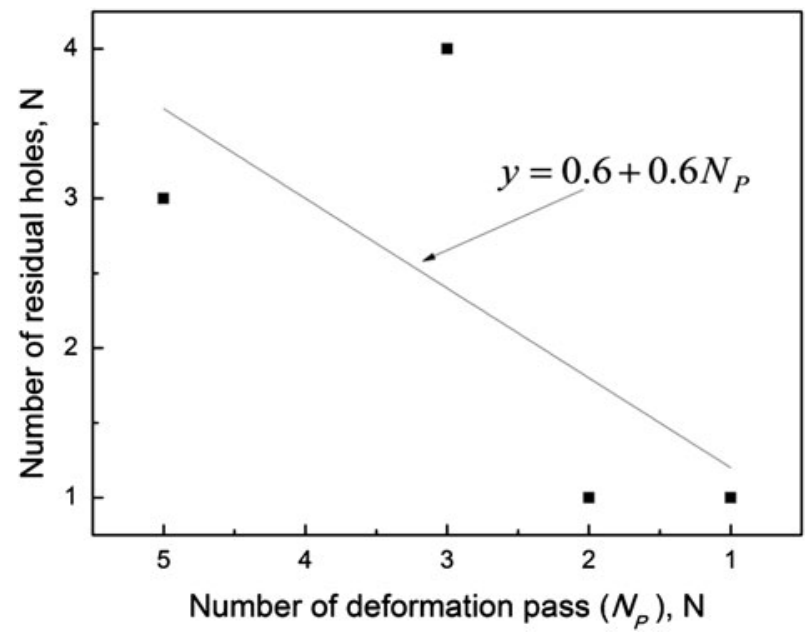

Fig. 7-Number of residual holes in the crack healing zone after deformation as a function of number of deformation passes at the same identical total reduction ratio.

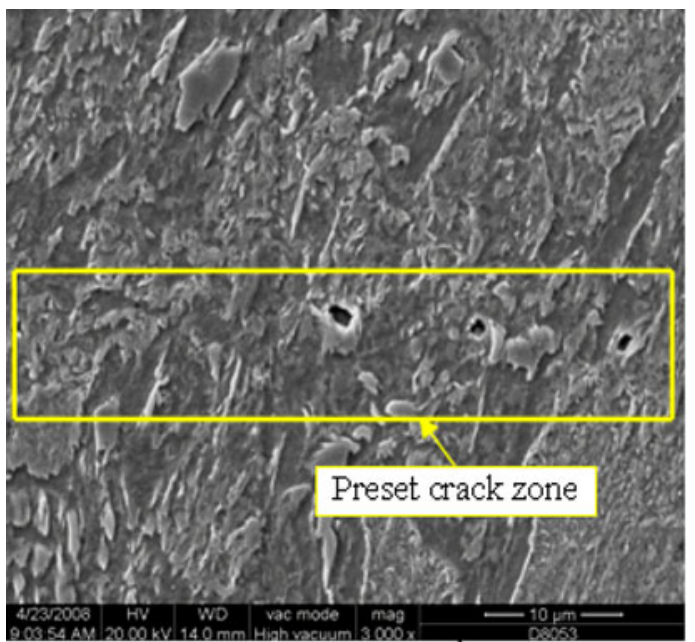

(a) $15 \mathrm{~s}^{-1}$

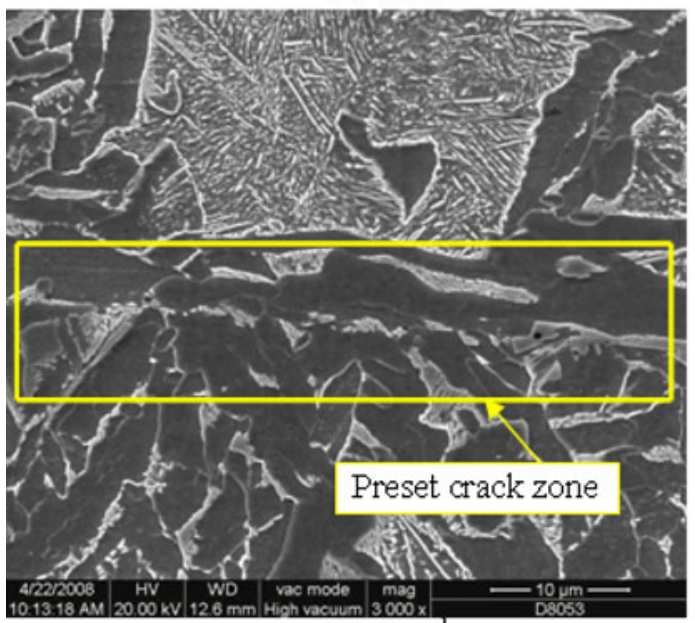

(c) $1 \mathrm{~s}^{-1}$ to the short-range Van der Waals forces, the deformation in every pass will just occur at the sample surface when the number of deformation pass is large enough; the total deformation reaches the set reduction ratio after multi-pass deformation, and the deformation at the center of sample will be still small, which will result in lots of holes remaining in the preset crack zone, thus the crack healing degree decreases.

\section{Influence of Strain Rate}

Figure 8 shows SEM micrographs of the preset internal crack zone after compressive deformation at various strain rates. When the strain rate is $15 \mathrm{~s}^{-1}$, there are holes which are distributed linearly at the preset crack zone and the size of holes is large. When the strain rate is $5 \mathrm{~s}^{-1}$, the number of small holes decreases, and crack healing improves. When the strain rate is $1 \mathrm{~s}^{-1}$, the crack healing degree in the preset crack zone improves further. It is difficult to detect the holes visually in Figure $8(\mathrm{c})$. When the strain rate is $0.01 \mathrm{~s}^{-1}$, the crack healing degree is the highest, and the transitional zone cannot be visually identified.

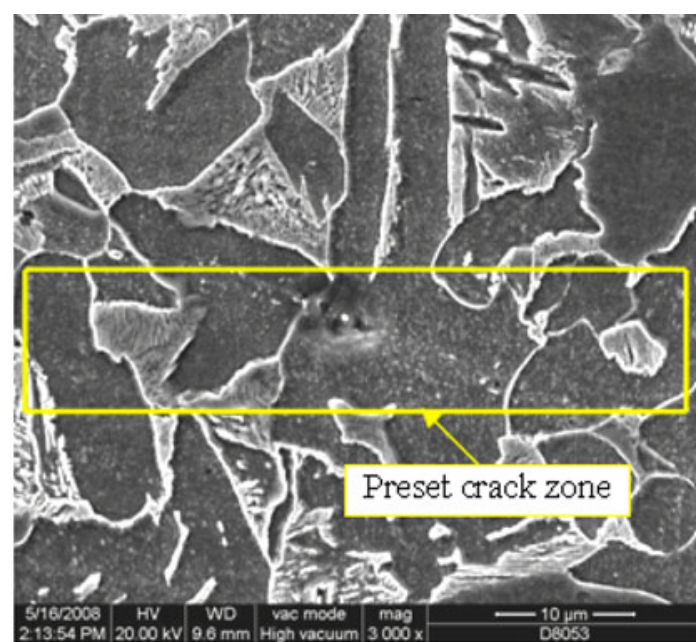

(b) $5 \mathrm{~s}^{-1}$

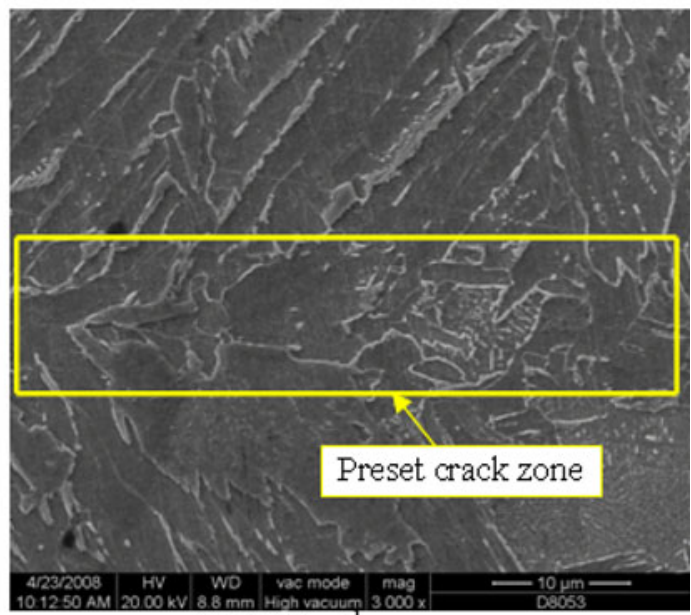

(d) $0.01 \mathrm{~s}^{-1}$

Fig. 8- SEM micrographs of crack healing for various strain rates. 
The relationship between the number of residual holes and the strain rate is shown in Figure 9. With reduction in the strain rate, the number of holes in the preset crack

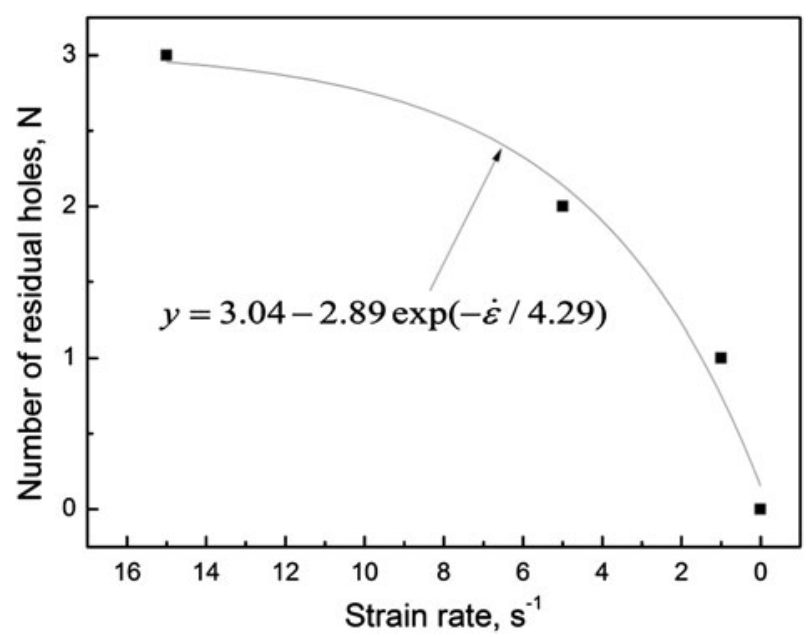

Fig. 9-Number of residual holes in the crack healing zone after deformation as a function of strain rates.

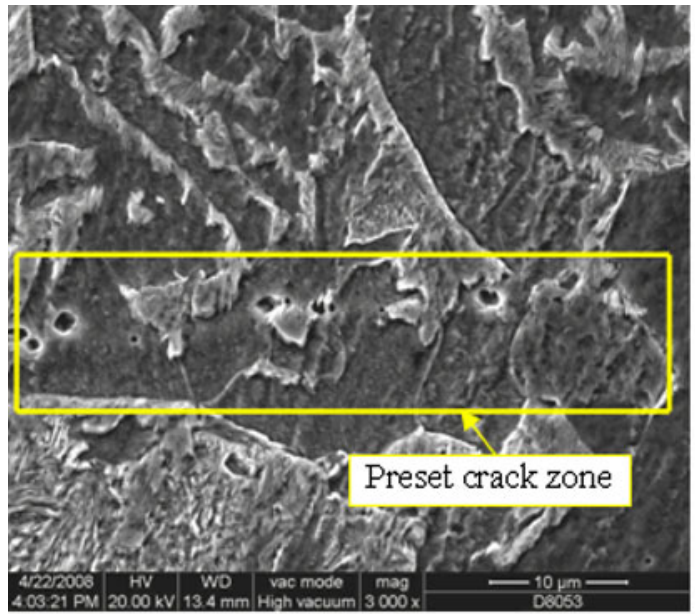

(a) $1 \mathrm{~min}$

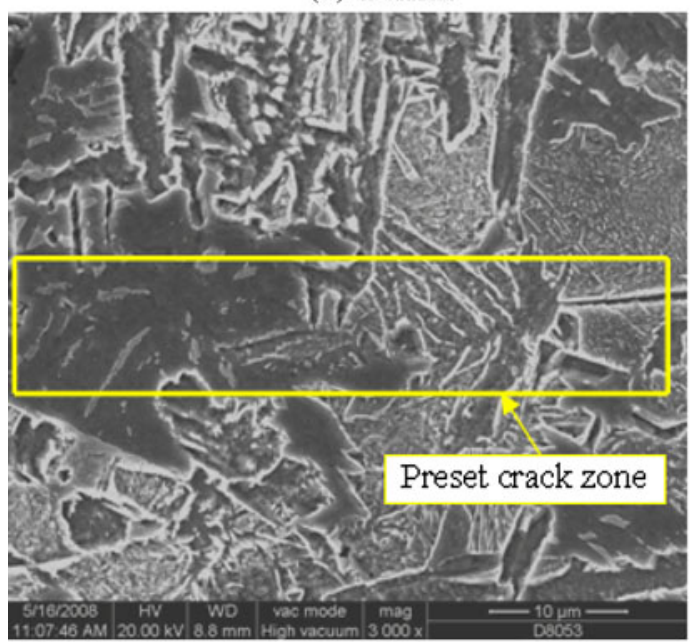

(c) $10 \mathrm{~min}$ zone obviously decreases, and the crack healing degree increases. The atomic diffusion coefficient on the crack surfaces and recrystallization around the preset crack zone are affected by the strain rate. Elimination of the gap between crack surfaces is affected by recrystallization in the preset crack zone. First, the nucleus deforms, and then the grain grows. In the grain growing process, the necessary material is moved by diffusion from the matrix. So, a new weak zone might emerge near the crack surface. If the recrystallization occurs rapidly, then the atoms far away from the crack surfaces cannot diffuse immediately. So some holes will remain in the preset crack zone. As the strain rate increases, the holes increase in size/number and the degree of crack healing decreases. In addition, with increasing strain rate, the holding time for crack healing will decrease. As seen in the following section, holding time is one of the main factors influencing crack healing. The shorter the holding time, the less adequate is the atomic diffusion. The average distance between atoms is directly proportional to the square root of diffusion time, as shown in Eq. [4]:

$$
X=K \sqrt{\tau},
$$

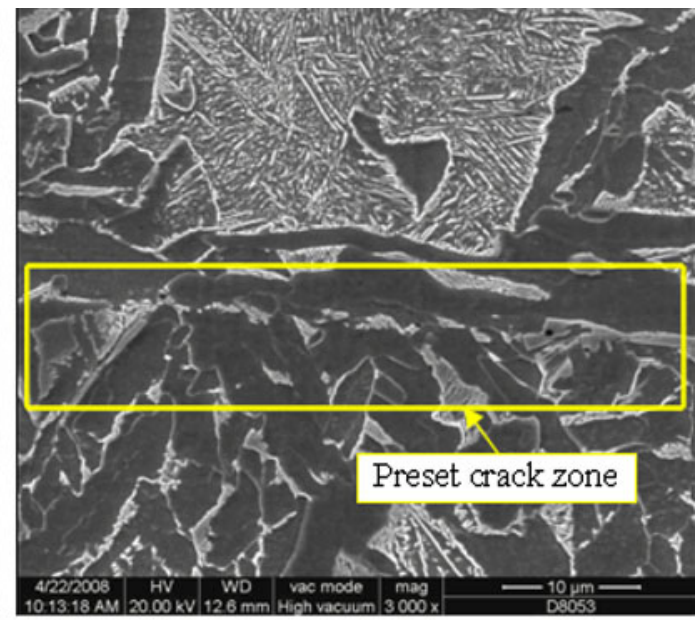

(b) $5 \mathrm{~min}$

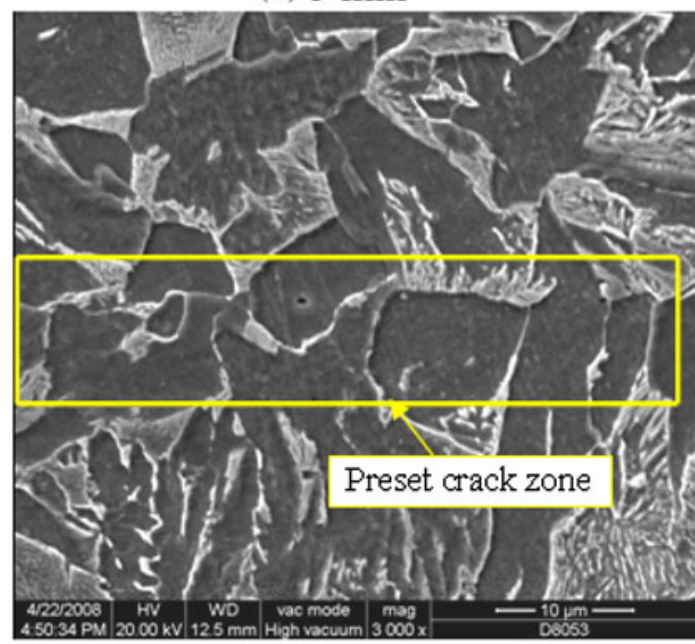

(d) $20 \mathrm{~min}$

Fig. 10 - SEM micrographs of crack healing zone for various holding time durations. 
where $X$ is the average migration distance of the atomic diffusion $(\mathrm{mm}) ; \tau$ is the diffusion time $(\mathrm{s}) ; K$ is the constant related to material $\left(\mathrm{mm} \mathrm{s}^{-1 / 2}\right)$.

\section{E. Influence of Holding Time}

Figure 10 shows SEM micrographs of the preset internal crack zone after compressive deformation for different holding time durations. When the holding time is 1 minute, there remain some holes linearly distributed in the preset crack zone. When the holding time is 5 minutes, there are new grains formed in the preset crack zone, but there still is an obvious transitional zone of crack healing. When the holding time is 10 minutes, the transitional zone becomes unclear, and the size of the holes decreases. When the holding time reaches 20 minutes, the grain size in the preset crack zone is similar to that of the matrix, and the crack heals quite well. These results show that the degree of crack healing improves with extension of the holding time.

Figure 11 shows the relationship between the number of residual holes and the holding time. For longer holding time durations, the number of residual holes reduces greatly.

With extension of holding time, there is sufficient opportunity for atomic diffusion to occur around the preset crack zone, leading to crack healing, and uniformity in the microstructure. According to the Fick's second law of diffusion,

$$
\frac{\partial C}{\partial t}=D \frac{\partial^{2} C}{\partial x^{2}}
$$

that is, the atomic concentration $C$ is a function of the diffusion distance $x$ and the diffusion time $t$. The diffusion distance is directly proportional to the square root of the diffusion time, as shown in Eq. [4]. The holding time at the beginning of crack healing plays a key role, and its effect gradually decreases with extension of the holding time. As far as its contribution to atomic diffusion is concerned, the effect of holding time is just

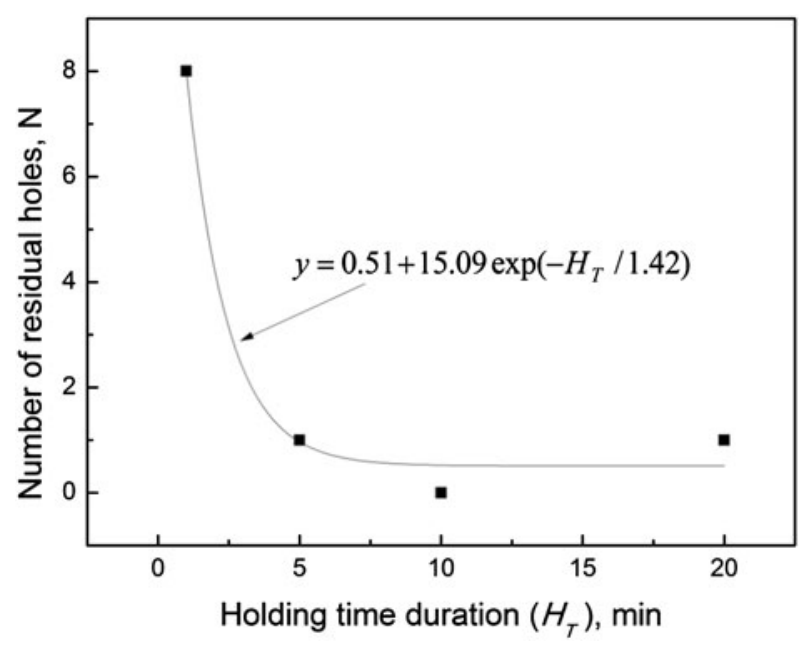

Fig. 11-Number of residual holes in the crack healing zone after deformation as a function of holding time durations. less than that of heating temperature. The heating time clearly impacts the crack healing in the beginning and the cracks can heal completely if the heating time is long enough.

\section{CONCLUSIONS}

(1) Crack healing in low-carbon steel samples under plastic deformation was simulated using the MMS 200 thermo-mechanical simulator. When the degree of crack healing is low, only ferrite appears in the crack healing transitional zone, and the microstructure between the transitional zone and the matrix gradually becomes uniform with increasing crack healing degree.

(2) The degree of crack healing in the middle of the preset crack zone of samples after compressive deformation increases when the heating temperature rises from $1173 \mathrm{~K}$ to $1473 \mathrm{~K}\left(900{ }^{\circ} \mathrm{C}\right.$ to $1200{ }^{\circ} \mathrm{C}$ ), especially in the range $1173 \mathrm{~K}$ to $1273 \mathrm{~K}$ $\left(900{ }^{\circ} \mathrm{C}\right.$ to $\left.1000{ }^{\circ} \mathrm{C}\right)$.

(3) When the reduction ratio increased from 0 to 50 pct, the number of holes in the preset crack zone decreases, the crack healing transitional zone narrows, and the microstructure difference between the transitional zone and the matrix decreases.

(4) The degree of crack healing increases with a reduction in the number of deformation passes and a reduction in the strain rate, and with the duration of the holding time.

\section{ACKNOWLEDGMENTS}

The lead author gratefully acknowledges the financial support from the Vice-Chancellor's Fellowship Grant at the University of Wollongong, the National Natural Science Foundation of China through Grant 51105071, and the Doctorate Foundation of the Ministry of Education of China through the Grant 20090042120005.

\section{REFERENCES}

1. K.M. Subramanian and P. Chandramohan: Mater. Manuf. Process., 2012, vol. 27, pp. 996-1000.

2. H. Xie, Z. Jiang, and W.Y.D. Yuen: Metall. Mater. Trans. B, 2011, vol. 42B, pp. 1244-52.

3. K.W. Nam and J.S. Kim: J. Ceram. Process. Res., 2010, vol. 11, pp. 20-24.

4. R. Girard, A. Faivre, and F. Despetis: J. Am. Ceram. Soc., 2011, vol. 94, pp. 2402-07.

5. L. Yao, Y.C. Yuan, M.Z. Rong, and M.Q. Zhang: Polymer, 2011, vol. 52, pp. 3137-45.

6. A. Hosoi, T. Nagahama, and Y. Ju: Mater. Sci. Eng. A, 2012, vol. 533, pp. 38-42.

7. X.G. Zheng, Y.N. Shi, and K. Lu: Mater. Sci. Eng. A, 2013, vol. 561, pp. 52-59.

8. Y. Zhang and J. Han: Met. Sci. Heat Treat., 2012, . DOI:10.1007/ s11041-012-9428-0.

9. F. Li, J. Pan, and A. Cocks: J. Am. Ceram. Soc., 2012, . DOI:10.1111/j.1551-2916.2012.05420.x. 
10. V.L. Kolmogorov and S.V. Smirnov: J. Mater. Process. Technol., 1998, vol. 74, pp. 83-88.

11. H.L. Zhang, P.Z. Huang, J. Sun, and H. Gao: Appl. Phys. Lett., 2004, vol. 85, pp. 1143-45.

12. D. Wei, J. Han, Z. Jiang, C. Lu, and K.A. Tieu: J. Mater. Process. Technol., 2006, vol. 177, pp. 233-37.

13. S.J. Li, M.Y. Sun, H.W. Liu, and D.Z. Li: Acta Metall. Sin., 2011, vol. 47 , pp. $946-53$.
14. S. Hautakangas, H. Schut, N. van Dijk, P. Castillo, and S. van der Zwaag: Scripta Mater., 2008, vol. 58, pp. 719-22.

15. H.L. Yu and X.H. Liu: Mater. Manuf. Process., 2009, vol. 24, pp. 570-80.

16. H.L. Yu, K. Tieu, C. Lu, G.Y. Deng, and X.H. Liu: Int. J. Adv. Manuf. Technol., 2012, . DOI:10.1007/s00170-012-4556-7.

17. M.D. Hager, P. Greil, C. Leyens, S. van der Zwaag, and U.S. Schubert: Adv. Mater., 2010, vol. 22, pp. 5424-30. 